\title{
A study of adjustment and emotional intelligence of university coaches in India
}

\author{
Mandeep Singh Nathial \\ Dept. of Higher Education, Government. of J \& K, Jammu, India \\ Email address: \\ bawarayman@yahoo.co.in
}

\section{To cite this article:}

Mandeep Singh Nathial. A Study of Adjustment and Emotional Intelligence of University Coaches in India. American Journal of Applied Psychology. Vol. 3, No. 6, 2014, pp. 122-126. doi: 10.11648/j.ajap.20140306.11

\begin{abstract}
The purpose of the study was to examine the differences between state and central university coaches of India in their level of adjustment and emotional Intelligence. A random sample was selected from 42 different state and central recognized universities of India from different states. Two hypotheses for the study include (1) There is no significant difference in the adjustment of university coaches belonging to state and central universities of India and (2) There is no significantly difference in the Emotional intelligence of university coaches belonging to state and central universities of India. Tools employed were Saxena's Adjustment Inventory and Mangal Emotional Intelligence Inventory that served as the main data sources. Critical Ratio was applied to get the results. It was observed that the mean scores of state university coaches in India $(\mathrm{m}=52.4)$ was higher than the mean scores of central university coaches in India $(\mathrm{m}=50.29)$ which further means that coaches belonging to state universities have better adjustment than the coaches belonging to central universities. It was also found that state and central university coaches did not differ significantly in their level of emotional-intelligence.
\end{abstract}

Keywords: State University, Central University, Adjustment and Emotional Intelligence

\section{Introduction}

Mal-adjustment is a common problem in the present time among sports persons. Life presents a continuous chain of struggle for existence and survival. Every one strives hard for satisfying own needs. Emotional intelligence (EI) has been defined as the ability to perceive, understand, and manage emotions (Salovey \& Mayer, 1989-1990), and is assumed to be related to the ability of self-regulation (Martinez-Pons, 1999-2000) It has been suggested that EI is a factor of paramount importance in adjustment to life in general, and to work and work performance in particular (Goleman, 1995, 1998). The concept has spread quickly in the popular press and among human resource consultants. The popular accounts by Goleman have later been found to be questionable (Matthews, Zeidner, \& Roberts, 2002). Yet, there have been studies giving some support to a relationship between EI and life success (Brackett \& Mayer, 2013; Brackett, Mayer \& Warner, 2014). Following these earlier work, there is a continuing interest in Emotional Intelligence and various aspects of life adjustment. Sports coaches assist athletes in developing to their full potential. They are responsible for training athletes in a sport by analyzing their performances, instructing in relevant skills and by providing encouragement. Coaches are also responsible for the guidance of the athlete in life and their chosen sport. Consequently, the role of the coach will be many and varied, from instructor, assessor, friend, mentor, facilitator, chauffeur, demonstrator, adviser, supporter, fact finder, motivator, counselor, organizer, planner and the Fountain of all Knowledge. (topendsports-2014). The United Kingdom Coaching Strategy describes the role of the sports coach as one that "enables the athlete to achieve levels of performance to a degree that may not have been possible if left to his/her own endeavours". Dyson speaking to the 19th session of the International Olympic Academy, Greece 1979, widened the horizon when he said that "the wise coach develops not only the fullest physical potential in his charges, but also those capacities and habits of mind and body which will enrich and ennoble their later years". As a coach one will initially need to develop the skills of: organising, safety, building rapport, providing instruction and explanation, demonstrating, observing, analysing, questioning and providing feedback. This study is also an attempt to undergo emotional intelligence and adjustment level of university (private \& Govt.) coaches.

Adjustment is a continuous process by which a person 
varies his or her behaviour to produce a more harmonious relationship between himself and his environment. Adjustment is a process that takes us to lead a happy and contented life. Adjustment gives us the strength and ability to bring advisable changes in the conditions of the environment. There are various areas where a person has to adjust with his or her educational, social, emotional, home and health aspects of life. Life is all about adjustment. Adjusting to conditions, situations and diverse ventures of life makes a man happy and adjusted [1, 4]. Of all the animals, man has been the most successful in the constant struggle with the environment. Even though he cannot run as fast as quadriceps, swim as like dolphin, climb as like as apes or fly as birds do. He has been the only creature, able to defy the force of gravity and move into outer space. Now a day, sport has become an essential part of the life. Millions of fans follow different sports events all over the world with enthusiasm and devotion. People participates in sports and games for many reasons, some play for fun, pleasure, happiness, health and fitness while some play as professionalists. Human beings normally run, jump, throw, catch, kick, strike and perform a multitude of basic skills. They learn these first as general skills and latter in modified specified sports skills. Then they combine the skill into patterns of increasingly greater specificity and complexity with the assistance of a coach. [13,14,15,17].

Human beings are creatures of feelings and emotions. If there had been no emotions in the life of organism, the life would have been without any aspirations. And also in the absence of emotion, social and family life would have ceased and progress would have been checked. The term "EMOTION" has been derived from the Latin word 'Emovere' which means to stir up, agitate, excite and move. Emotions have been referred to as the 'dynamics of behaviour' which term refers to the energies of forces that initiate activity. Emotion in the organism is the dynamic interval adjustment that operates for the satisfaction and welfare of the individual. If animal do something they call it instinct. If we do exactly the same thing for same reason they call it intelligence. I feel what they mean is that we all make mistakes, but intelligence enables us to do it on purpose. An encompassing defection has given by D. Wechsler(1943) "Intelligence is the aggregate or global capacity of the individual to act purposefully, to think rationally, and to deal effectively with his environment."

The process of adjustment starts right from the birth and continuous till adulthood. Man, among the living beings; has the highest capacity to adapt to new situations. Man as a social animal not only adapts to physical demands but also adjusts to social pressures. This adjustment means reaction to the demands and pressures of social environment, imposed upon the individual. The demand may be external or internal to whom the individual has to react (Chauhan 1978). Adjustment therefore is a process which leads us to a happy and contented life, maintains a balance between our needs and the capacity to meet these needs and persuades us to change our way of life according to the demands of the situation. (Mangal 1984).Emotional Intelligence is that which gives a person a competitive edge. It refers to the capacity for recognizing our own feelings and those of others, for motivating ourselves and for managing emotions well in us and in our relationships. $[13,6,7,9]$ It describes abilities distinct from, but complementary to academic intelligence, the purely cognitive capacities measured by IQ. It is often said that a high IQ may assure us a top position, but it may not make us a top person. Pioneering model of emotional intelligence was proposed in the 1980's by Reuven Bar-on, an Israeli psychologist. His model describes emotional intelligence as "an array of personal, emotional, social abilities that influence one's ability to succeed in coping with environmental demands and pressures." [14]

Objectives of the Study

- To examine the difference between state and central university coaches of India in their level of adjustment.

- To study the difference between state and central university coaches of India in their level of Emotional Intelligence.

Hypotheses

- There is no significant difference in the adjustment of university coaches belonging to state and central universities of India.

- There is no significant difference in the Emotional intelligence of university coaches belonging to state and central universities of India.

\section{Methodology}

\section{Selection of sample}

The sample was randomly drawn from 42 different state and central recognized universities in India. The total sample representing the population is 300 coaches. The study was restricted to total scores of Adjustment and Emotional intelligence. The study was conducted on university coaches who knew Hindi and English both languages, as one questionnaire i.e.Saxena's Adjustment inventory was in Hindi and other i.e. Mangal Emotional Intelligence Inventory was in English. In the study, Adjustment Inventory and Mangal Emotional Intelligence Inventory were administered to collect the data. The university coaches were asked to fill the Adjustment Inventory was also asked to fill the Mangal Emotional Intelligence Inventory i.e., both the inventories were to be filled by the same individual. At the time of actual administration of the test, necessary steps were adopted to get the accurate scoring. They were informed that their responses will be kept confidential and therefore, they should be frank and bold in answering the question.

The aims and the responses of the study were explained to the university coaches in order to ensure reliable responses and they were told that their responses will be utilized for research work and would be kept confidential. The investigator administered two sets one after the other. After giving them proper instructions and guidance the university coaches were asked to finish their work as soon as possible. Before administering the tests the investigator carefully noted that the place for the administration of the test was such that coaches walked comfortably and without disturbance. 
Language used by the investigator in giving instructions to the coaches was very simple

\section{Instruments}

- Saxena's Adjustment inventory, (By M.S.L. Saxena): The investigator has elected Saxena's Adjustment Inventory for measuring the adjustment of the university coaches. This is widely used inventory particularly for adjustment studies the inventory is in Hindi. The main reason for taking this test was high reliability and validity. Saxena's Adjustment inventory consists of 90 items. The items are in question form and the responses are recorded as "Yes", "?", "N". The inventory was easy to administer and quite easy to score. It takes about 25 to 30 minutes to answer all the questions. It can be administered to an individual as well as to a group.

- Mangal Emotional Intelligence Inventory (By S.K. Mangal and Shubhra Mangal): This inventory contains 100 items seeking responses in "Yes" or "No" the subjects were asked to give any type of response from those against each item by enriching them. The inventory was not time bound and the subjects were asked to answer all the items. After the completion of the test all the booklets were collected with the help of one or two students.

Data Analysis

Scoring scheme of Saxena's Adjustment Inventory: The scoring of this Adjustment Inventory was done according to prescribed scoring keys offered for Vyaktitva Pariksha Prishnawali (Hindi), by the author of the test M.S.L. Saxena. The correct answer for each element in "Yes", "No" forms as allotted to each element was given one mark each. In this way Adjustment scores of all the 300 coaches were obtained. The high the scores obtained the good is adjustment of the coach.

Scoring Procedure of Mangal Emotional Intelligence Inventory: Emotional Intelligence consists of 100 items which are followed by "Yes" or "No" one positive score is awarded for one tick mark on an item. Yes' items are counted and the total number of 'Yes' items marked by the coaches was the level of intelligence. In the administration of the test, the purpose of the test was made clear to the coaches so that the participation shall remain serious and to the best responses. For finding the significance of difference in various groups with respect to independent variable, the investigator applied Critical Ratio to the data available. SPSS software is used as tool to find out the results and further analysis.

\section{Results}

To examine the difference between state and central university coaches of India in their level of adjustment and emotional Intelligence, after application of required statistical techniques, results were analyzed.

It is revealed in Table 1 that the Critical Ratio of the mean scores adjustment between state and central university coaches in India is significant at 0.01 level. Therefore they differ significantly in their level of adjustment. It is observed that the mean scores of state university coaches in India $(\mathrm{m}=$
52.4) is higher than the mean scores of central university coaches in India $(m=50.29)(\mathrm{CR}=4.22)$ which further means that coaches belonging to state universities have better adjustment than the coaches belonging to central universities.

It is clearly indicated in Table 2 that the critical ratio of the mean scores of emotional-intelligence between state and central university coaches in India is not significant even at 0.05 level. As the calculated value of CR i.e. 0.96 is less than 1.96 which is the t-value table at 0.05 level. Therefore it can be inferred that state and central university coaches do not differ significantly in their level of emotional-intelligence.

Table 1. Critical Ratio of mean Scores of Adjustment of coaches belonging to State and Central Universities.

\begin{tabular}{lllllllll}
\hline S.No. & University & Mean & & N & m & DM & DM & CR \\
\hline 1. & State & 52.4 & 4.4 & 150 & 0.36 & & & \\
2. & Central & 50.29 & 4.2 & 150 & 0.34 & & & \\
\hline
\end{tabular}

*Significant at 0.01 level.

Table 2. Critical Ratio mean scores of Emotional Intelligence of Students belonging to State andCentral universities.

\begin{tabular}{|c|c|c|c|c|c|c|c|c|}
\hline S.No. & University & Mean & & $\mathbf{N}$ & m & DM & DM & CR \\
\hline 1. & State & 58.93 & 4.9 & 150 & 0.4 & \multirow{2}{*}{0.57} & \multirow{2}{*}{0.55} & \multirow{2}{*}{0.96 Insig. } \\
\hline 2. & Central & 58.38 & 4.9 & 150 & 0.4 & & & \\
\hline
\end{tabular}

\section{Discussion}

Adjustment of coaches belonging to state and central universities in India was found significantly different. Coaches from both types of universities are not facing the same pay grades and time schedules that may be the reason of significant differences among the coaches in adjustment level. In the previous study also, conducted by Sheetal (1993) with the purpose of examining the adjustment of primary and government school teachers of Jammu City in north India and significant differences were found. On the other hand the level of emotional intelligence of state and central university coaches in India do not differ significantly. Minimum academic and professional eligibility of the coaches from both types of universities are same and this may be the reason of not having any significant differences among the coaches in the level of emotional intelligence. In a previous study Raina (2010) explored the relationship of emotional intelligence and academic achievement among players and found that a low relationship between emotional intelligence and academic achievement. In case of emotional intelligence, an investigation by David Akinlolo (2014) a significant relationship between emotional intelligence and adjustment of students transitioning from primary school to secondary school. It was also found in the same study that the strengths of emotional intelligence, defined in terms of high, moderate and low, significantly impacted the adjustment of students. The result also needs to consider the related work of Sjoberg (2001) whose finding demonstrated significant relationship between emotional intelligence and life adjustment. The 
finding is also supported by the work of Greenberg, Kusche, Cook and Quamma (1995). In the study by Dhiman Kar, Birbal Saha \& Bhim Mondal (2014) that provides an insight about emotional intelligence and gender differences. Results of this study presented that there is no significant relationships between emotional intelligence among boys and girls but significant difference exist for rural and urban secondary students.

\section{Conclusions}

It is evident that the level of adjustment between state and central university coaches in India is significantly differ at 0.01 level. But the level of emotional intelligence of state and central university coaches in India do not differ significantly. Hence the Hypothesis stating that 'There will be no significant difference in the adjustment of coaches belonging to state and central universities in India' is rejected and the Hypothesis stating that 'There will be no significant difference in the Emotional intelligence of coaches belonging to state and central universities in India' is accepted. The current results have important implications for the development of emotional Intelligence in social as well as sports development. This kind of intervention should be built into orientation programmes for fresh sports coaches. The focus of such intervention should be on problematic areas such as Coaching, Sport Sciences, academic and social adjustment, organizational issues, pupil perception, school phobia and other transition traumas.

\section{Acknowledgements}

As the study covers wide range of private and Govt. universities, Author is thankful to the coaches of the respective universities that that cooperated in fair way. Further I respect my students who worked for me to make this study possible. I am grateful to LNIPE, Punjabi Univ. and Panjab Univ. faculty and coaches specifically.

\section{References}

[1] Adu, Cecilia Adurayemi, 'Cooperative Societies in Nigeria: Prospects and Problems', International Journal of Behavioral social and Movement Sciences, Vol.03, July, Issue03, pp50-55, 2014

[2] Anuradha Dhar \& Raju Jaiswal, 'A Study on Sports Achievement Motivation Among State Level Kho-Kho Players', International Journal of Research Pedagogy and Technology in Education and Movement Sciences (ijems), Vol.03,Issue03,Sept,pp20-26,2014

[3] Barchard, K.A. and Hakstian, A.R., "The Relation of Emotional Intelligence of Traditional Cognitive and Personality Variables." Paper presented at the Annual Convention of the Canadian psychological Association ste-foy Quebec, 2014.

[4] Brackett \& Mayer, Discriminant, and Incremental Validity of Competing Measures of Emotional Intelligence. Personality \& Social Psychology Bulletin, 29, 2013, 1147-1158.
[5] Basu, G, "Comparative Study of Personality Characteristics of Tibeban and East Pakistani Backward Refugee Children," Unpublished Ph.D. Thesis, Patna University. 1985.

[6] David Akinlolo, 'The buffering effect of emotional intelligence on the adjustment of secondary school students in transition', Electronic Journal of Research in Educational Psychology. ISSN: 1696-2095. No 6 -3 (2), pp. 79-90

[7] Dewan, A.M. "Effect of Stress, locality and Gender on selected Cognitive Non-Cognitive Variables," Ph.D. Education, P.U.Chandigarh, 2012.

[8] Dhiman Kar, Birbal Saha \& Bhim Mondal, American Journal of Educational Research, 20142 (4), pp 193-196. DOI: 10.12691 /education-2-4-3

[9] Finnegam, J.E., "Measuring Emotional Intelligence:" where we are today Montogmery, A.L: Auburn University at Montgomery, School of Education (ERIC Document Reproduction service No. ED 426087)m 2014.

[10] Furukawat: Shbayamat; Conducted a Study on "Factors Influencing Adjustment of High School Students.

[11] Go swami, U.N and Jayapoorni, "Emotional Adjustment of Youth In Relation To Sex, Locality and Income In Assam.” Indian psychological Abstract, 25(2), 1986.

[12] Goleman, D. (1998). Working with emotional intelligence. New York: Bantam Books.

[13] Greenberg, M.T., Kusche, C.A., Cook, E.T. \& Quamma, J.P. 'Promoting emotional competence in school-aged children'. The effects of PATHS curriculum. Curriculum and Psychopathology, 1995, 7, 117-136.

[14] Henery E. Gerrett.(1979) Statistics in psychology and education.paragon international Publishers,New Delhi.

[15] Jamwal, Ruchika , "A Study of Adjustment In Relation To Reasoning Ability and Sex Among High School Students," unpublished M.Ed. dissertation, University of Jammu. 2014

[16] Kaur, Surinder J.T and Kaur Harjit , "Teacher's Efforts To Promote Emotional Intelligence Among Adolescent Students." University News, 44(39), September.', 2006

[17] Kaur, surinder, Jit and Kaur Harjit, "Teacher's Efforts To Promote Emotional Intelligence, Among Adolescent Students," University, News, 44(39), September 25-October, 01., 2006

[18] Khajuria, A.R. "A Study of Relationship Among Certain Areas Of Adjustment." Unpublished Dissertation, M.Ed. Students, Jammu, 2013.

[19] Mandeep Singh Nathial, Analysis of Set Shot in Basketball in Relation with Time to Perform the Course and Displacement of Center of Gravity, American Journal of Sports Science. Vol. 2, No. 5, 2014, pp. 122-126. doi: 10.11648/j.ajss.20140205.13

[20] Mangal, S.K (2003) Advanced Educational Psychology, Prentice. Hall of India, Pvt. Ltd. New Delhi.

[21] Matthews, G., Zeidner, M., \& Roberts, R. D. (2002). Emotional intelligence: science and myth. Boston, MA: MIT Press

[22] Neale, Steve, Lisa Spencer-Arnell, Liz Wilson. Emotional Intelligence Coaching 
[23] Ram Prakash Gupta \& Satish Kumar Walia, 'Study of Personality in Relation to Emotional Intelligence of Pupil Teachers', International Journal of Research Pedagogy and Technology in Education and Movement Sciences (ijems), vol.02,Issue04,June,pp39-46,2014

[24] Rani, Subha, “A Study Of Adjustment In Relation To Sex And Academic Achievement, unpublished M.A. Education Dissertation, University of Jammu., 2002

[25] Sjoberg, L., 'Emotional Intelligence and life adjustment: A validation report'. SSE/EFI Working paper series in business administration No. 2001:8.

[26] Summerfeldt, L. J., Kloosterman, P. H., Antony, M. M., \& Parker, J. D. A. (2006). Social anxiety, emotional intelligence, and interpersonal adjustment. Journal of Psychopathology and Behavioral Assessment, 28, 57-68.

[27] Terrell, James Bradford, Marcia Hughes. A Coach's Guide to Emotional Intelligence

[28] Vadnais, A. M. (2005). The relationship of emotional intelligence and marital satisfaction. Dissertation Abstracts International: Section B: The Sciences and Engineering, 66(1-B), 579

[29] Verma, L.K. and Sharma, N.R., "Advanced Statistics In
Education And Psychology." Narendra Publishing House, Jalander, 1990

[30] J. Clerk Maxwell, A Treatise on Electricity and Magnetism, 3rd ed., vol. 2. Oxford: Clarendon, 1892, pp.68-73.

[31] I. S. Jacobs and C. P. Bean, "Fine particles, thin films and exchange anisotropy," in Magnetism, vol. III, G. T. Rado and H. Suhl, Eds. New York: Academic, 1963, pp. 271-350.

[32] K. Elissa, "Title of paper if known," unpublished.

[33] Omid Salimzade, Reza Pourhosein \& Masoud Lavasani, 'Investigating the Effectteaching Mindfulness-Based Stress Reduction in Reducing Pschological Symptoms in Adolescent Boys in Dorms, International Journal of Behavioral Social and Movement Sciences, vol.03,oct.,Issue04,pp44-58,2014

[34] R. Nicole, "Title of paper with only first word capitalized," J. Name Stand. Abbrev., in press.

[35] U.S. Bureau of the Census. Child support and alimony: 1987. Current Population Reports, Series P-23, No. 167. Washington, DC: U.S. Government Printing Office, 1990.

[36] Yoo, S. H., Matsumoto, D., \& LeRoux, J. A. The influence of emotion recognition and emotion regulation on intercultural adjustment. International Journal of Intercultural Relations, $30,2006, \quad 345-363$. 